\title{
Correlation of carotid blood flow and corrected carotid flow time with invasive cardiac output measurements
}

\author{
Irene W. Y. Ma ${ }^{1,2^{*}}$, Joshua D. Caplin ${ }^{3}$, Aftab Azad ${ }^{1,4}$, Christina Wilson', Michael A. Fifer ${ }^{3}$, Aranya Bagchi ${ }^{5}$, \\ Andrew S. Liteplo ${ }^{1}$ and Vicki E. Noble ${ }^{1,6}$
}

\begin{abstract}
Background: Non-invasive measures that can accurately estimate cardiac output may help identify volumeresponsive patients. This study seeks to compare two non-invasive measures (corrected carotid flow time and carotid blood flow) and their correlations with invasive reference measurements of cardiac output. Consenting adult patients $(n=51)$ at Massachusetts General Hospital cardiac catheterization laboratory undergoing right heart catheterization between February and April 2016 were included. Carotid ultrasound images were obtained concurrently with cardiac output measurements, obtained by the thermodilution method in the absence of severe tricuspid regurgitation and by the Fick oxygen method otherwise. Corrected carotid flow time was calculated as systole time $/ \sqrt{ }$ cycle time. Carotid blood flow was calculated as $\pi \times$ (carotid diameter $)^{2} / 4 \times$ velocity time integral $\times$ heart rate. Measurements were obtained using a single carotid waveform and an average of three carotid waveforms for both measures.
\end{abstract}

Results: Single waveform measurements of corrected flow time did not correlate with cardiac output ( $\rho=0.25,95 \%$ $\mathrm{Cl}-0.03$ to $0.49, p=0.08)$, but an average of three waveforms correlated significantly, although weakly $(\rho=0.29,95 \%$ $\mathrm{Cl} 0.02-0.53, p=0.046$ ). Carotid blood flow measurements correlated moderately with cardiac output regardless of if single waveform or an average of three waveforms were used: $\rho=0.44,95 \% \mathrm{Cl} 0.18-0.63, p=0.004$, and $\rho=0.41$, $95 \% \mathrm{Cl} 0.16-0.62, p=0.004$, respectively.

Conclusions: Carotid blood flow may be a better marker of cardiac output and less subject to measurements issues than corrected carotid flow time.

Keywords: Cardiac output, Carotid ultrasound, Carotid flow time, Carotid blood flow

\section{Background}

To be able to identify patients who are fluid responsive is important in the management of those who are acutely ill. At present, there is no non-invasive method that can reliably and accurately identify fluid responsiveness. As such, in patients with undifferentiated shock, treatment often involves empiric fluid administration, in the hopes that volume expansion will increase preload, which will then serve to increase cardiac output (CO). However, for patients on the flat portion of the Starling curve, aggressive fluid

\footnotetext{
*Correspondence: ima@ucalgary.ca

2 Division of General Internal Medicine, Department of Medicine, University of Calgary, 3330 Hospital Dr NW, Calgary, AB T2N 4N1, Canada Full list of author information is available at the end of the article
}

administration results in no appreciable increase in $\mathrm{CO}$ and may be detrimental [1-3]. Thus, the ability to identify where each patient is on his/her Starling curve can help identify patients who would benefit from additional fluid (fluid responsive) and those who would not (fluid unresponsive). Unfortunately, traditional measures of preload such as central venous pressure have not consistently been shown to be helpful in identifying volume responsiveness $[4,5]$. The use of pulse pressure variation shows promise in ventilated patients, but requires the insertion of an arterial line [5]. As such, there remains a pressing need to be able to identify fluid responsiveness non-invasively at the bedside.

Fluid responsiveness is typically defined as an increase in CO by $10-15 \%$ in response to fluid administration [6]. 
To avoid excess fluid administration, an increase of $\mathrm{CO}$ in response to maneuvers such as the passive leg raise (PLR) is considered indicative of fluid responsiveness [7]. PLR is typically performed with the patient either in the supine or semirecumbent position, followed by repeat measurements with the patient's legs passively raised at 30-45 [7]. This maneuver is considered to result in an auto-bolus of fluid of approximately $300 \mathrm{~mL}$ in volume [8]. The benefit of the PLR is that its hemodynamic effects are rapidly reversible, since no fluid administration actually takes place.

Cardiac output, however, has been challenging to measure at the bedside. The traditional reference standard for measuring $\mathrm{CO}$ requires the insertion of a pulmonary artery catheter $[5,9]$ which is invasive, associated with a risk for serious complications [10], and its use may offer no clinical benefits [11-15]. Newer non-invasive devices using bioreactance parameters have mixed evidence in their accuracy and reliability [16-20], and require a dedicated machine that may not be readily available. Lastly, estimations of $\mathrm{CO}$ using echocardiography have been suggested as a bedside measure. However, its use may not be feasible due to high training requirements [21].

In the quest to identify feasible, non-invasive, and reproducible bedside estimates of CO, carotid Doppler imaging shows promise. In particular, two carotid measurements have emerged as candidate markers of $\mathrm{CO}$ : corrected carotid flow time (CFT) and carotid blood flow (CBF). CFT is the carotid systole time, with heart rate correction applied. This measure is easy to perform and may correlate with intravascular volume [22]. CBF is the integral of blood volume that is ejected through the carotid artery with each cardiac cycle. This measure has been shown to be feasible to perform at the bedside [23, 24].

Studies to date have shown that corrected CFT increases in response to fluid administration or consumption $[25,26]$, and decreases in response to volume removal in dialysis [22] and blood donation [27]. However, none of these studies correlated corrected CFT with CO. CBF has been less extensively studied. However, in one study of 34 patients, a change in CBF in response to PLR was found to correlate significantly with a change in stroke volume index, measured by bioreactance [28].

Despite these promising studies, neither measure has been correlated directly with a commonly used invasive reference standard for measuring $\mathrm{CO}$ via the pulmonary artery catheter. As such, this study seeks to compare corrected $\mathrm{CFT}$ and $\mathrm{CBF}$ with invasive measures of $\mathrm{CO}$.

\section{Methods}

All adult patients at Massachusetts General Hospital cardiac catheterization laboratory undergoing right heart catheterization between February and April 2016 were invited to participate. Non-consenting patients, patients on mechanical ventilation, and those unable to tolerate a passive leg raise (PLR) maneuver were excluded (e.g., unable to lie supine or had pain with PLR).

Carotid ultrasound images were obtained concurrently with $\mathrm{CO}$ measures with the patient in the supine position. A PLR was then performed by elevating the legs using a standardized $30^{\circ}$ foam wedge (RayShield ${ }^{\circledR}$ AADCO Medical Inc., Vermont). Repeat carotid ultrasound images and concurrent $\mathrm{CO}$ measurements were then obtained within 1 min after PLR, as maximal blood flow changes were felt to be observed within $1 \mathrm{~min}[8,29]$.

Carotid ultrasound images were obtained by an emergency ultrasound fellow (I.M.). Images were obtained using a linear-array (15-4 MHz) transducer on a bedside ultrasound system (uSmart ${ }^{\circledR}$ Terason 3200T, Burlington, MA). The carotid vascular preset was used (pulse repetition frequency $5.0 \mathrm{kHz}$, wall filter $75 \mathrm{~Hz}$ ). The common carotid artery was scanned in transverse and longitudinal planes. Spectral Doppler tracings were then obtained by placing a $0.5 \mathrm{~mm}$ sample gate through the center of vessel, within $2-3 \mathrm{~cm}$ proximal to the carotid bulb in the longitudinal plane, in accordance to standard guidelines [30]. The angle correction cursor was placed parallel to the direction of blood flow. Images with insonation angles $>60^{\circ}$ were excluded because of resultant inaccuracies of flow and velocity measurements at such angles [31].

\section{Carotid measurements}

Corrected CFT was calculated as systole time $/ \sqrt{ }$ cycle time [27]. Systole time was measured from the start of systolic upstroke to the start of the dicrotic notch, while cycle time was the duration of the cycle (Fig. 1a).

CBF was calculated as

$$
\begin{aligned}
\text { blood flow }= & \pi \times(\text { carotid diameter })^{2} / 4 \\
& \times \text { VTI } \times \text { heart rate, }
\end{aligned}
$$

where VTI indicates velocity time integral [28]. VTI of the Doppler signal was measured using manual tracings (Fig. 1b). Intimal-to-intimal carotid diameter was measured at the level of the sample gate (Fig. 1b).

All carotid measurements (systole time, cycle time, VTI, diameter) were measured on a single waveform by one investigator (I.M.) in order to calculate corrected CFT and CBF. Average corrected CFT and average CBF were then calculated using a mean of three waveforms. To establish interrater reliability on obtaining measurements, all measurements on obtained images were then repeated by a second independent investigator (C.W. or A.A., both with similar training to I.M.), who was blinded to all $\mathrm{CO}$ and carotid measurements. Results from the second investigator were used only to provide interrater reliability estimates. 


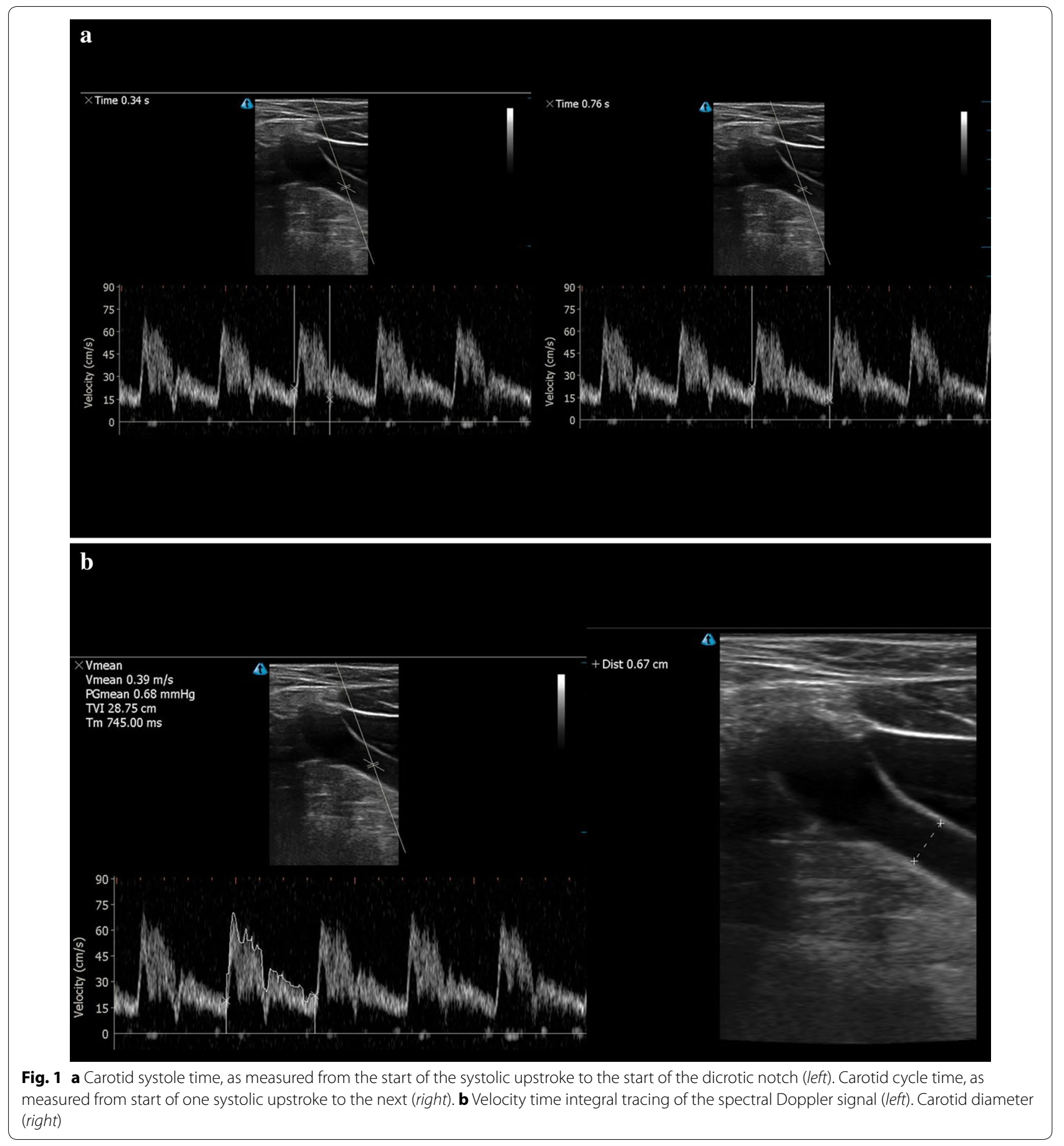

Image acceptability was rated independently by two trained raters (C.W., A.A.), using five domains (internal reliability acceptable, Cronbach's alpha $=0.84$ ): correction angle parallel to vessel, sample gate in the center of the vessel, sufficient gain, vessel was non-oblique, and measurements made within $2-3 \mathrm{~cm}$ proximal to carotid bulb (see Additional file 1). All domains were rated using a 5-point Likert scale, where $1=$ poor quality and $5=$ excellent quality, with overall image quality rated as a summary measure, based on global expert opinion.

Cardiac output measurements were obtained by thermodilution method in the absence of severe tricuspid regurgitation, by an injection of $10 \mathrm{~mL}$ of sterile $0.9 \%$ saline injection into the proximal lumen of the 
pulmonary artery catheter and subsequent detection of the temperature change at the distal thermistor [32]. Fick oxygen method was used in the presence of severe tricuspid regurgitation [33]. The Fick method involved simultaneous arterial and mixed venous blood sample measurement, and cardiac output was determined based upon the ratio between estimated oxygen consumption and arteriovenous oxygen gradient [34]. Post hoc analyses of correlation measures were performed in subgroups of patients in and not in atrial fibrillation at the time of the procedure.

This study was approved by the Partners Human Research Committee Institution Review Board.

\section{Statistical analysis}

On the basis of Marik et al.s prior study on estimates of stroke volume indices correlations with carotid blood flow [28], we estimated that 26 patients would have $90 \%$ power to detect a correlation of $0.59(\alpha=0.05)$. However, as interim analyses revealed a lower than 0.59 correlation in our study sample. A repeat sample size calculation suggested that an estimated 48 patients would be needed to detect a correlation of $0.45(\alpha=0.05$, power $=0.9)$.

Pre- and post-PLR measurements were compared using paired $t$ tests and Wilcoxon signed-rank tests, as appropriate. Correlations between $\mathrm{CO}$ and carotid parameters were made using Spearman's rho, a non-parametric correlation coefficient. Confidence intervals around Spearman's rho were based on Fisher's $r$ to $\mathrm{z}$ transformation [35]. Correlation coefficients of $0.10-0.29$ were considered weak, $0.30-0.49$ as moderate, and $0.50-1.00$ as strong [36]. All $p$ values were adjusted for multiple comparisons using the Benjamini-Hochberg procedure [37], which allows the false discovery rate to be controlled at the 0.05 level.

All analyses were performed using SAS 9.4 (SAS Institute Inc. Cary, NC) and SPSS version 24 (IBM Corp. Armonk, NY).

\section{Results}

Of the 67 eligible patients, 51 patients (76\%) were included in the final analysis (Fig. 2; Table 1). The majority of patients had cardiac output measurements done using thermodilution ( $n=44 ; 86 \%)$. Five patients were excluded because of angles of insonation of $>60^{\circ}$. Of the included 51 patients, median angle of insonation was $60^{\circ}$, with a range of $38-60^{\circ}$. Overall image quality of the included patients was rated as above-average quality [mean score $4.1 \pm$ standard deviation (SD) 0.6] based on global expert opinion. As there were no differences in $\mathrm{CO}$, corrected CFT, or CBF between pre- and postPLR maneuver (Table 2), only baseline measures (i.e., pre-PLR) will be further discussed. Interrater reliability

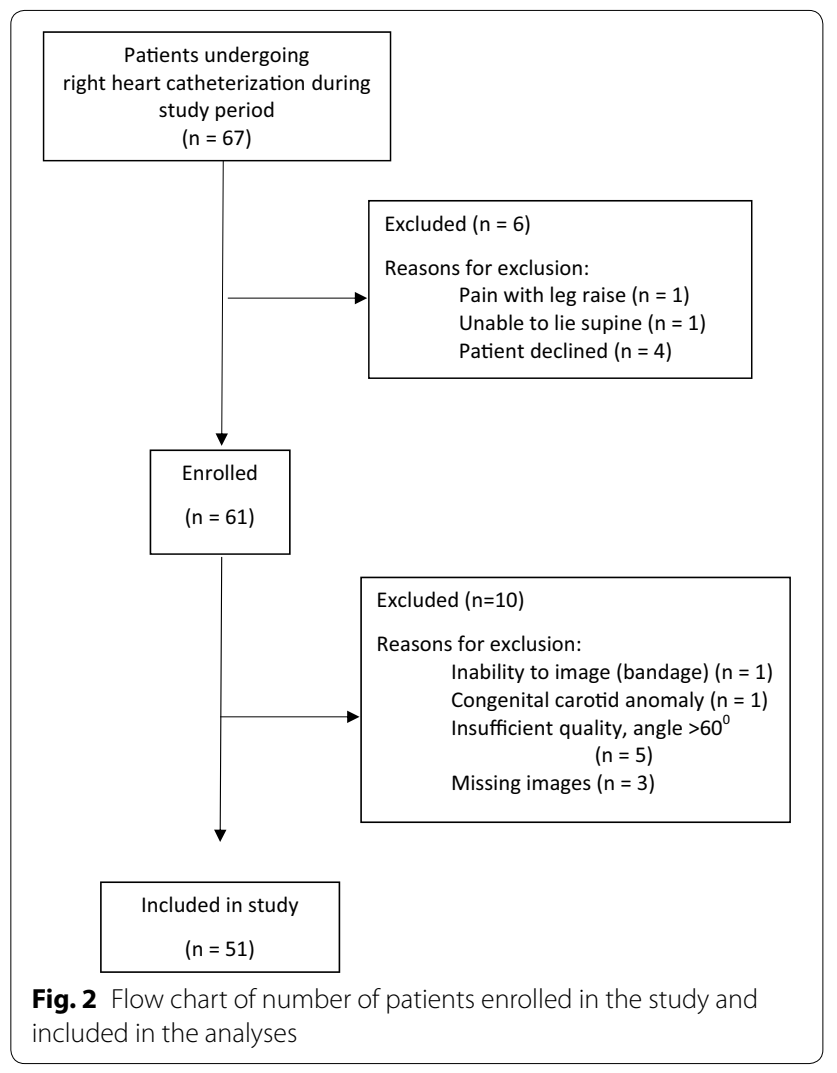

for corrected CFT and CBF measurements on obtained images was excellent [intraclass correlation coefficient (ICC) 0.90, 95\% CI 0.82-0.94; ICC 0.96, 95\% CI $0.58-$ 0.99 , respectively].

\section{Corrected carotid flow time (CFT)}

Single waveform measurements of corrected CFT did not correlate with $\mathrm{CO}$ measurements $[\rho=0.25$, 95\% confidence interval $(\mathrm{CI})-0.03$ to 0.49 , adjusted $p=0.08$ ] Corrected CFT measurements using three waveforms correlated significantly, but weakly, with CO $(\rho=0.29$, 95\% CI 0.02-0.53, adjusted $p=0.046)$.

\section{Carotid blood flow (CBF)}

Single waveform CBF correlated moderately and significantly with $\mathrm{CO}[\rho=0.44,95 \%$ CI $0.18-0.63$, adjusted $p=0.004$ ). CBF measurements using three waveforms also moderately and significantly correlated with $\mathrm{CO}$ $(\rho=0.41,95 \%$ CI $0.16-0.62$, adjusted $p=0.004)$.

\section{Subgroup analysis}

In a subgroup of patients not in atrial fibrillation at the time of the procedure $(n=45)$, single waveform measurements of corrected CFT did not correlate with $\mathrm{CO}$ ( $\rho=0.26,95 \% \mathrm{CI}-0.04$ to 0.51 , adjusted $p=0.17$ ). For patients in atrial fibrillation at the time of the procedure 
Table 1 Baseline characteristics of 51 patients included in the study

\begin{tabular}{ll}
\hline Baseline characteristics & Number (\%) \\
\hline Mean age in years \pm standard deviation & $59.6 \pm 16.3$ \\
Gender & \\
Male & $39(76)$ \\
Female & $12(24)$ \\
Body mass index (kg/m $\left.{ }^{2}\right) \pm$ standard deviation & $26.3 \pm 5.9$ \\
History of & \\
Diabetes mellitus & $13(25)$ \\
Hypertension & $26(51)$ \\
Dyslipidemia & $22(43)$ \\
Coronary artery disease & $17(33)$ \\
Prior angioplasty and/stent placement & $7(14)$ \\
Prior coronary bypass surgery & $4(8)$ \\
Stroke or transient ischemic attacks & $11(22)$ \\
Atrial fibrillation & $13(25)$ \\
Moderate or severe aortic insufficiency & $1(2)$ \\
Moderate or severe aortic stenosis & $5(10)$ \\
Indication for right heart catheterization & \\
Diagnostic right heart catheterization only & $24(47)$ \\
Cardiac biopsy & $27(53)$ \\
Cardiac output measurement method & \\
Thermodilution & $44(86)$ \\
Fick oxygen method & $7(14)$ \\
Vascular access & \\
Forearmal jugular & $40(78)$ \\
Femoral & $5(10)$ \\
\hline
\end{tabular}

$(n=6)$, single waveform corrected CFT measurements did not correlate with $\mathrm{CO}(\rho=0.09,95 \% \mathrm{CI}-0.78$ to 0.84 , adjusted $p=0.88$ ). In patients not in atrial fibrillation $(n=45)$, corrected CFT measurements using three waveforms correlated moderately and significantly with CO $(\rho=0.33,95 \%$ CI $0.04-0.56$, adjusted $p=0.03)$. In patients in atrial fibrillation $(n=6)$, corrected CFT measurements using three waveforms did not correlate with $\mathrm{CO}(\rho=-0.14,95 \% \mathrm{CI}-0.86$ to 0.76 , adjusted $p=0.92)$.
Single waveform measurements of CBF correlated moderately and significantly with $\mathrm{CO}$ in patients not in atrial fibrillation at the time of the procedure $(\rho=0.42$, $95 \%$ CI $0.15-0.64$, adjusted $p=0.03$ ). For the six patients in atrial fibrillation, single waveform measurements did not correlate with CO $(\rho=0.66,95 \%$ CI -0.33 to 0.96 , adjusted $p=0.28$ ). In patients not in atrial fibrillation $(n=45), \mathrm{CBF}$ measurements using three waveforms correlated moderately and significantly with $\mathrm{CO}(\rho=0.40$, $95 \%$ CI $0.12-0.62$, adjusted $p=0.02$ ). For the six patients in atrial fibrillation at the time of the procedure, $\mathrm{CBF}$ measurements using three waveforms did not correlate with $\mathrm{CO}(\rho=0.60,95 \% \mathrm{CI}-0.41$ to 0.95 , adjusted $p=0.31$ ).

\section{Self-report feasibility}

Overall, reported ease of carotid diameter measurement was high (mean score $4.1 \pm$ SD 0.8 , where $1=$ very difficult and $5=$ very easy). Reported ease of measuring VTI tracings was moderate (mean score $3.5 \pm$ SD 0.8). Ease of systole time was moderate (3.7 \pm SD 0.8$)$ and high for cycle time (4.2 \pm SD 0.7).

\section{Discussion}

In this study of 51 adult patients undergoing invasive right heart catheterization and simultaneous carotid ultrasound, CBF correlated moderately and significantly with $\mathrm{CO}$. This relationship was present whether a single waveform or an average of three waveforms was used. Corrected CFT, on the other hand, when measured using only a single waveform, as per the method used by prior studies [22, 25-27], demonstrated no correlation with $\mathrm{CO}$. Only by measuring three waveforms was corrected carotid flow time's correlation with $\mathrm{CO}$ significant. However, the strength of this relationship was weak. Altogether, our findings suggest CBF may be a better surrogate marker for $\mathrm{CO}$ and that $\mathrm{CBF}$ measurements may be less subject to measurements issues than corrected CFT.

The ability to estimate $\mathrm{CO}$ in an accurate, reliable, and feasible manner is an important part of determining patients' volume responsiveness. Carotid ultrasound is

Table 2 Baseline mean cardiac output and median carotid ultrasound parameters (corrected flow time and blood flow) pre- and post-passive leg raise

\begin{tabular}{|c|c|c|c|}
\hline Parameter & $\begin{array}{l}\text { Pre-passive leg raise median } \\
\text { (interquartile range) }\end{array}$ & $\begin{array}{l}\text { Post-passive leg raise median } \\
\text { (interquartile range) }\end{array}$ & $p$ value \\
\hline Mean cardiac output \pm standard deviation (SD) (L/min) & $5.15 \pm 1.58$ & $5.19 \pm 1.58$ & 0.69 \\
\hline Corrected flow time (single waveform in milliseconds) & $331.7(308.6-357.8)$ & $344.2(321.6-360.6)$ & 0.06 \\
\hline Corrected flow time (average of three waveforms in milliseconds) & $335.2(311.0-359.3)$ & $339.6(322.1-368.9)$ & 0.13 \\
\hline Blood flow (single waveform in mL/min) & $576.3(389.5-806.9)$ & $551.77(441.5-763.5)$ & 0.45 \\
\hline Blood flow (average of three waveforms in mL/min) & $555.4(422.1-766.6)$ & $558.3(452.7-741.6)$ & 0.45 \\
\hline
\end{tabular}


a promising tool for two reasons. First, unlike the traditional reference standard of $\mathrm{CO}$ measurement from a pulmonary artery catheter [5, 9], carotid ultrasound imaging is non-invasive and readily available in many centers. Second, as evidenced by reported ease of measurements in our study, and confirmed by prior studies [23, 24], carotid ultrasound is easy to perform. This is in contrast to echocardiographic measures of $\mathrm{CO}$ [21], which requires more extensive training [38], as its accuracy is dependent on scan techniques and patient factors such as obesity and availability of sonographic windows [39].

In deciding whether to use corrected CFT or CBF as an estimate of $\mathrm{CO}$, one should consider the following factors: (1) strength of the correlation with reference standard, (2) contextual factors that may limit its accuracy, (3) reliability, (4) feasibility, and (5) sensitivity in detecting $\mathrm{CO}$ changes. We argue that $\mathrm{CBF}$ is superior for the first two factors, and that both CBF and corrected CFT demonstrated high interrater reliability and feasibility.

To our knowledge, ours is the first study to compare both carotid ultrasound measures with invasive measures of $\mathrm{CO}$. Our study demonstrates that CBF correlates stronger than corrected CFT with $\mathrm{CO}$ and is less sensitive to measurements errors. We hypothesize that two sources of errors may be contributing to measurement errors in corrected CFT: cardiac arrhythmia and underlying cardiac conditions.

With respect to the cardiac arrhythmia hypothesis, we noted that corrected CFT measurements based on averaging three waveforms yielded a higher and significant correlation, compared to measurements based only on one waveform. The potential of respiratory contribution to the variations in cycle time and systole time (sinus arrhythmia) may contribute to this finding. The hypothesis regarding the contribution of arrhythmias to inaccurate measurements was further supported by findings from our subgroup analysis, whereby the correlation of corrected CFT with $\mathrm{CO}$ became significant in a subgroup of patients not in atrial fibrillation at the time of the procedure, and only if an average of three waveforms were used. Correlations were lower in general for patients in atrial fibrillation compared with those not in atrial fibrillation, whether a single waveform or three waveforms were used. Indeed, prior studies evaluating corrected carotid flow time excluded patients with atrial fibrillation [22, 25-27]. In our subgroup analysis of patients in atrial fibrillation, we were unable to detect significant correlations with cardiac output measurement regardless of whether CBF or corrected CFT was used, and regardless of whether a single waveform or an average of three waveforms was used. However, our small sample size $(n=6)$ is likely too small to demonstrate a significant correlation. Future studies should evaluate the use of these parameters in patients in atrial fibrillation. Until such studies are performed, it may be prudent to continue to exclude patients with significant cardiac arrhythmia when attempting to use carotid measurements as surrogates for CO.

With respect to the cardiac condition hypothesis, it is noteworthy that measurements of systole time require the identification of the start of the dicrotic notch. Valvular diseases are known to affect carotid tracings, which may render the dicrotic notch more difficult to appreciate [40-42]. Indeed, in our study, self-report ease of measuring cycle time was higher than for systole time, which may be a reflection of the difficulty in identifying the dicrotic notch in certain cases. Carotid blood flow, on the other hand, utilizes more clinical parameters (diameter, VTI, and heart rate) that may be less subject to the changes of any single parameter and may therefore more accurately estimate for the volumetric flow of blood through the carotid. For example, adaptation to a lower VTI may be accommodated by a larger carotid diameter and/or a faster heart rate. Therefore, accounting for these additional parameters may result in an overall more accurate estimate.

There are a number of limitations in our study. First, this is a single-centered study. Second, we are able to report only interrater reliability for image interpretation and not for image acquisition (a single sonographer performed all the scanning). Image acquisition by untrained sonographers may potentially result in unacceptable interrater reliability. Future studies should examine image acquisition interrater reliability and the role of training. Third, as our patients were largely euvolemic, PLR maneuvers resulted in no demonstrable changes in any of our measured parameters. Therefore, we cannot comment on the sensitivity of carotid measurements to changes imposed by dynamic maneuvers. Further, our use of a $30^{\circ}$ foam wedge rather than the more commonly used $45^{\circ}$ leg lift [7] may have further limited our ability to induce significant changes preand post-PLR. In addition, although it has been argued that the maximal blood flow changes occur within one minute $[8,29]$, the majority of studies evaluating PLR use a longer time frame [7]. The optimal timing remains unclear. Fourth, our subgroup analysis of patients in and not in atrial fibrillation was performed in a post hoc manner. Results from these analyses should be considered as hypothesis generating only. Fifth, our carotid VTI measurements were performed manually. Therefore, measurement errors may be present. However, measurement errors would be expected to dilute correlation coefficients towards the null [43]. Because many machines are equipped with automatic VTI tracings, correlation coefficients for CBF measured in an automated manner may yield higher correlations than those 
reported in our study. Sixth, we do not have information on the history of carotid disease. Therefore, we are unable to determine the impact of carotid disease on the accuracy of our carotid ultrasound measurements. Last but not least, the majority of our patients underwent the thermodilution method for cardiac output estimation. While its use is commonly accepted as the practical gold standard, its use is not without limitations, especially in the presence of significant tricuspid regurgitation, intracardiac shunts, or concurrent intravenous infusions $[9,44,45]$.

\section{Conclusions}

Our study demonstrates that compared to corrected CFT, CBF demonstrated stronger and more consistent correlation with $\mathrm{CO}$. Its use for assessing volume responsiveness should be further evaluated.

\section{Additional file}

Additional file 1. Carotid artery doppler quality assessment tool (CADQAD).

\begin{abstract}
Abbreviations
CBF: carotid blood flow; CFT: carotid flow time; CO: cardiac output; Cl: confidence interval; ICC: intraclass correlation coefficient; PLR: passive leg raise; SD: standard deviation; VTI: velocity time integral.
\end{abstract}

\section{Authors' contributions}

IWYM contributed to conception and design, acquisition of data, analysis, interpretation of data, and drafting and revision of article. JDC, AA, CW, and MAF contributed to acquisition of data and interpretation of data and revision of article. $A B$ and $A S L$ contributed to conception and design, interpretation of data, and revision of article. VEN contributed to conception and design, acquisition of data, interpretation of data, and drafting and revision of article. All authors have provided final approval of the version submitted. All authors read and approved the final manuscript.

\section{Author details}

1 Division of Emergency Ultrasound, Department of Emergency Medicine, Massachusetts General Hospital, 326 Cambridge Street, Suite 410, Boston, MA 02114, USA. ${ }^{2}$ Division of General Internal Medicine, Department of Medicine, University of Calgary, 3330 Hospital Dr NW, Calgary, AB T2N 4N1, Canada. ${ }^{3}$ Cardiology Division, Department of Medicine, Massachusetts General Hospital, 15 Parkman Street \#800, Boston, MA 02114, USA. ${ }^{4}$ Department of Emergency Medicine, Hamad Medical Corporation, PO Box 3050, Doha, Qatar. ${ }^{5}$ Department of Anaesthesia, Massachusetts General Hospital, 55 Fruit Street, Boston, MA 02114, USA. ${ }^{6}$ Department of Emergency Medicine, University Hospitals, Cleveland Medical Center, Case Western Reserve University, 11100 Euclid Ave, Cleveland, $\mathrm{OH}$ 44106, USA.

\section{Acknowledgements}

The authors would like to thank all the colleagues and patients at the Massachusetts General Hospital cardiac catheterization laboratory for their collaboration and participation in this work.

\section{Competing interests}

The authors declare that they have no competing interests.

\section{Availability of data and materials}

The datasets generated and/or analyzed in this study are not currently publicly available but are available from the corresponding author on reasonable request.
Ethics approval and consent to participate

This study was approved by the Partners Human Research Committee Institution Review Board (protocol \# 2015P002076/MGH).

\section{Funding}

Dr. Irene W. Y. Ma was funded by the University of Calgary Research and Scholarship Leave Grant. The funder has no role in the design and conduct of this study; in the collection, management, analysis, and interpretation of the data; or in the preparation, review, and approval of the manuscript.

\section{Publisher's Note}

Springer Nature remains neutral with regard to jurisdictional claims in published maps and institutional affiliations.

Received: 8 January 2017 Accepted: 11 April 2017

Published online: 20 April 2017

\section{References}

1. Kelm DJ, Perrin JT, Cartin-Ceba R, Gajic O, Schenck L, Kennedy CC (2015) Fluid overload in patients with severe sepsis and septic shock treated with early-goal directed therapy is associated with increased acute need for fluid-related medical interventions and hospital death. Shock 43:68-73

2. Boyd JH, Forbes J, Nakada TA, Walley KR, Russell JA (2011) Fluid resuscitation in septic shock: a positive fluid balance and elevated central venous pressure are associated with increased mortality. Crit Care Med 39:259-265

3. Acheampong A, Vincent J-L (2015) A positive fluid balance is an independent prognostic factor in patients with sepsis. Crit Care 19:251

4. Marik PE, Cavallazzi R (2013) Does the central venous pressure predict fluid responsiveness? An updated meta-analysis and a plea for some common sense. Crit Care Med 41:1774-1781

5. Bentzer P, Griesdale DE, Boyd J, MacLean K, Sirounis D, Ayas NT (2016) WIII this hemodynamically unstable patient respond to a bolus of intravenous fluids? JAMA 316:1298-1309

6. Bendjelid K, Romand JA (2012) Fluid responsiveness in mechanically ventilated patients: a review of indices used in intensive care. Intensive Care Med 29:352-360

7. Cavallaro F, Sandroni C, Marano C, La Torre G, Mannocci A, De Waure C, Bello G, Maviglia R, Antonelli M (2012) Diagnostic accuracy of passive leg raising for prediction of fluid responsiveness in adults: systematic review and meta-analysis of clinical studies. Intensive Care Med 36(9):1476-1483

8. Monnet $X$, Teboul JL (2015) Passive leg raising: five rules, not a drop of fluid! Crit Care 19:18

9. Pugsley J, Lerner AB (2010) Cardiac output monitoring: is there a gold standard and how do the newer technologies compare? Semin Cardiothorac Vasc Anesth 14:274-282

10. Dee Boyd K, Thomas SJ, Gold J, Boyd AD (1983) A prospective study of complications of pulmonary artery catheterizations in 500 consecutive patients. Chest 84:245-249

11. Harvey S, Harrison DA, Singer M, Ashcroft J, Jones CM, Elbourne D, Brampton W, Williams D, Young D, Rowan K (2005) Assessment of the clinical effectiveness of pulmonary artery catheters in management of patients in intensive care (PAC-Man): a randomised controlled trial. Lancet 366:472-477

12. Sandham JD, Hull RD, Brant RF, Knox L, Pineo GF, Doig CJ, Laporta DP, Viner S, Passerini L, Devitt H, Kirby A, Jacka M (2003) A Randomized, controlled trial of the use of pulmonary-artery catheters in high-risk surgical patients. N Engl J Med 348:5-14

13. Richard C, Warszawski J, Anguel N, Deye N, Combes A, Barnoud D, Boulain T, Lefort Y, Fartoukh M, Baud F (2003) Early use of the pulmonary artery catheter and outcomes in patients with shock and acute respiratory distress syndrome: a randomized controlled trial. JAMA 290:2713-2720

14. Shah MR, Hasselblad V, Stevenson LW, Binanay C, O'Connor CM, Sopko G, Califf RM (2005) Impact of the pulmonary artery catheter in critically ill patients: meta-analysis of randomized clinical trials. JAMA 294:1664-1670

15. Wheeler A, Bernard G, Thompson B, Schoenfeld D, Wiedemann H, DeBoisblanc B, Connors A Jr, Hite R, Harabin A (2006) Pulmonary-artery versus 
central venous catheter to guide treatment of acute lung injury. $\mathrm{N}$ Engl J Med 354:2213-2224

16. Benomar B, Ouattara A, Estagnasie P, Brusset A, Squara P (2010) Fluid responsiveness predicted by noninvasive bioreactance-based passive leg raise test. Intensive Care Med 36:1875-1881

17. Fagnoul D, Vincent J-L, Backer D (2012) Cardiac output measurements using the bioreactance technique in critically ill patients. Crit Care 16:460

18. Raval NY, Squara P, Cleman M, Yalamanchili K, Winklmaier M, Burkhoff D (2008) Multicenter evaluation of noninvasive cardiac output measurement by bioreactance technique. J Clin Monit Comput 22:113-119

19. Squara P, Denjean D, Estagnasie P, Brusset A, Dib JC, Dubois C (2007) Noninvasive cardiac output monitoring (NICOM): a clinical validation. Intensive Care Med 33:1191-1194

20. Kupersztych-Hagege E, Teboul JL, Artigas A, Talbot A, Sabatier C, Richard C, Monnet X (2013) Bioreactance is not reliable for estimating cardiac output and the effects of passive leg raising in critically ill patients. Br J Anaesth 111:961-966

21. Gunst M, Ghaemmaghami V, Sperry J, Robinson M, O'Keeffe T, Friese $R$, Frankel H (2008) Accuracy of cardiac function and volume status estimates using the bedside echocardiographic assessment in trauma/ critical care. J Trauma 65:509-516

22. Hossein-Nejad H, Mohammadinejad P, Lessan-Pezeshki M, Davarani SS, Banaie M (2015) Carotid artery corrected flow time measurement via bedside ultrasonography in monitoring volume status. J Crit Care 30:1199-1203

23. Stolz LA, Mosier JM, Gross AM, Douglas MJ, Blaivas M, Adhikari S (2015) Can emergency physicians perform common carotid Doppler flow measurements to assess volume responsiveness? W J Emerg Med 16:255-259

24. Adedipe AA, Fly DL, Schwitz SD, Jorgenson DB, Duric H, Sayre MR, Nichol G (2015) Carotid Doppler blood flow measurement during cardiopulmonary resuscitation is feasible: a first in man study. Resuscitation 96:121-125

25. Blehar DJ, Glazier S, Gaspari RJ (2014) Correlation of corrected flow time in the carotid artery with changes in intravascular volume status. J Crit Care 29:486-488

26. Shokoohi H, Berry GW, Shahkolahi M, King J, Salimian M, Poshtmashad A, Pourmand A (2016) The diagnostic utility of sonographic carotid flow time in determining volume responsiveness. J Crit Care 38:231-235

27. Mackenzie DC, Khan NA, Blehar D, Glazier S, Chang Y, Stowell CP, Noble VE, Liteplo AS (2015) Carotid flow time changes with volume status in acute blood loss. Ann Emerg Med 66:277-282

28. Marik PE, Levitov A, Young A, Andrews L (2013) The use of bioreactance and carotid doppler to determine volume responsiveness and blood flow redistribution following passive leg raising in hemodynamically unstable patients. Chest 143:364-370

29. Monnet X, Rienzo M, Osman D, Anguel N, Richard C, Pinsky MR, Teboul JL (2006) Passive leg raising predicts fluid responsiveness in the critically ill. Crit Care Med 34:1402-1407
30. American College of Radiology (2016) ACR-AIUM-SRU practice parameter for the performance of an ultrasound examination of the extracranial cerebrovascular system. http://www.acr.org/ /media/5d63a45f7a54417c 93cd58f109fofdd2.pdf. Accessed 5 Apr 2017

31. Tola M, Yurdakul M (2006) Effect of Doppler angle in diagnosis of internal carotid artery stenosis. J Ultrasound Med 25:1187-1192

32. Ganz W, Donoso R, Marcus HS, Forrester JS, Swan HJ (1971) A new technique for measurement of cardiac output by thermodilution in man. Am J Cardiol 27:392-396

33. Callan P, Clark AL (2016) Right heart catheterisation: indications and interpretation. Heart 102:147-157

34. Wilkinson JL (2001) Haemodynamic calculations in the catheter laboratory. Heart 85:113-120

35. Shen D, Lu Z (2006) Computation of correlation coefficient and its confidence interval in SAS. http://www2.sas.com/proceedings/sugi31/170-31. pdf. Accessed 5 Apr 2017

36. Cohen J (1988) Statistical power analysis for the behavioral sciences. Academic Press, New York

37. Benjamini Y, Hochberg Y (1995) Controlling the false discovery rate: a practical and powerful approach to multiple testing. J R Stat Soc B Methodol 57:289-300

38. Garcia X, Mateu L, Maynar J, Mercadal J, Ochagavía A, Ferrandiz A (2011) Estimating cardiac output. Utility in the clinical practice. Available invasive and non-invasive monitoring. Med Intensiva 35:552-561

39. Nicolosi GL, Pungercic E, Cervesato E, Pavan D, Modena L, Moro E, Dall'Aglio V, Zanuttini D (1988) Feasibility and variability of six methods for the echocardiographic and Doppler determination of cardiac output. Br Heart J 59:299-303

40. Madhwal S, Yesenko S, Kim ESH, Park M, Begelman SM, Gornik HL (2014) Manifestations of cardiac disease in carotid Duplex ultrasound examination. JACC 7:200-203

41. O'Boyle MK, Vibhakar NI, Chung J, Keen WD, Gosink BB (1996) Duplex sonography of the carotid arteries in patients with isolated aortic stenosis: imaging findings and relation to severity of stenosis. AJR Am J Roentgenol 166:197-202

42. Kallman C, Gosink B, Gardner D (1991) Carotid duplex sonography: bisferious pulse contour in patients with aortic valvular disease. AJR Am J Roentgenol 157:403-407

43. Kelsey JL, Whittemore AS, Evans AS, Thompson WD (1996) Methods in observational epidemiology. Oxford University Press Inc, New York

44. Lee AJ, Cohn JH (2011) Ranasinghe JS (2011) Cardiac output assessed by invasive and minimally invasive techniques. Anesthesiol Res Pract $17: 475151$

45. Marino PL (2014) The ICU Bok, 4th edn. Lippincott Williams \& Wilkins, Philadelphia

\section{Submit your manuscript to a SpringerOpen ${ }^{\circ}$ journal and benefit from:}

- Convenient online submission

- Rigorous peer review

- Immediate publication on acceptance

- Open access: articles freely available online

- High visibility within the field

- Retaining the copyright to your article

Submit your next manuscript at $\boldsymbol{\nabla}$ springeropen.com 